\title{
ART BRUT Y NATURALEZA: \\ DE FERDINAND CHEVAL A MÁXIMO ROJO
}

Data recepción: 2012/05/05

Data aceptación: 2012/07/17

Contacto autora: laura.pelayo@hotmail.com
Laura Pelayo González

Universidad Autónoma de Madrid

RESUMEN:

El objeto de este análisis es la relación que se establece entre los entornos brut y la naturaleza. Se parte de una breve introducción al art brut y a las construcciones, a medio camino entre la arquitectura y la escultura, que protagonizan esta investigación. Después, se ahonda en dos ejemplos concretos: el Palacio Ideal de Ferdinand Cheval y el jardín de esculturas de Máximo Rojo. Ambos servirán para concretar la vinculación de estas creaciones con el medio y las cuestiones fundamentales que surgen de la revalorización del hábitat. Se han escogido estos dos casos porque a través de su comparación se advierten dos paisajes diferenciados: la campiña francesa de Cheval a finales del siglo XVIII y principios del XIX, de donde él selecciona principalmente materiales naturales, y el mundo rural de Rojo en las últimas décadas del siglo XX, inseparable de la superproducción y el consumo.

Palabras clave: Ferdinand Cheval, Máximo Rojo, entorno, marginal, naturaleza

\section{ABSTRACT:}

This analysis takes as its subject the relationship established between outsider environments and nature. It begins with a brief introduction to art brut (outsider art) and the constructions that provide the focal point for this research study, which lie halfway between architecture and sculpture. It then discusses two specific examples in detail: Ferdinand Cheval's Palacio Ideal and Maximo Rojo's sculpture garden, both of which highlight the link between these creations and the environment, and the key issues arising from the revaluation of the habitat. The rationale for selecting these two cases is that two distinguishable landscapes were detected in comparing them: Cheval's French countryside of the late 18th- to early 19th-century, from which he selects natural materials in the main; and Rojo's rural world of the last decades of the 20th century, which are inseparable from overproduction and consumption.

Keywords: Ferdinand Cheval, Maximo Rojo, environment, outsider, nature.

En los márgenes de las carreteras, a las afueras de las grandes ciudades o en pequeños pueblos más o menos aislados, surgen construcciones que se elevan sobre lo esperado. Son locuras artísticas a manos de creadores autodidactas y desconocidos que realizan una única y monumental obra a lo largo de su vida en la que vuelcan todos sus anhelos y esperanzas. Éstas se entrelazan con el ambiente que los rodea, con sus árboles y piedras, pero también, en los ejemplos más recientes, con la basura que se amontona y pasa a ser reciclada en pro de una estética de acumulación, hibridación y equilibrio. Una historia incompleta marcada por el olvido y el expolio, que emerge en el Barroco y prolifera en los siglos $\mathrm{XX}$ y XXI. Arquitectura marginal, environments, art brut, escultecturas margivagantes, diferentes nombres para catalogar esta otra realidad artística, fantasiosa y atrevida, que habla del ser humano como animal creador, constructor de su hogar en sintonía con el entorno. 


\section{El art brut}

El objeto de este estudio se engloba dentro del art brut1. El artista Jean Dubuffet acuñó este término en los años cuarenta y lo definió como un arte espontáneo, ajeno a los cánones y circuitos artísticos, realizado principalmente por personas sin formación ${ }^{2}$. Para el autor francés estas obras no debían nada a la cultura, afirmación de gran polémica que fue matizando a lo largo de su trayectoria, llegando a asumir, finalmente, que una carencia total de este tipo de referentes era imposible. Dubuffet encontró en los pacientes de hospitales psiquiátricos, los médiums y los prisioneros a los máximos exponentes de esta otra creación con la que esperaba insuflar de aire nuevo a la Europa de posguerra. Ensalzó con su pluma la pureza y la vivacidad de enfermos mentales como Aloïse, Müller o Wöllfli, frente a la decadencia, la artificialidad y el mercantilismo de los círculos de profesionales parisinos. Su labor investigadora le llevó a formar una importante colección que dio a conocer a través de exposiciones y escritos. Fomentó el interés del público y animó a algunos iniciados a seguir sus pasos en el estudio y la promoción de este patrimonio de los excluidos.

Así, las publicaciones especializadas sobre este asunto se aceleraron en los años siguientes, dando lugar a una heterogeneidad creciente y a la aparición de nuevas nomenclaturas. En la bibliografía francófona destacan: art hors les normes (arte fuera de las normas), art singulier (arte singular) o création franche (creación franca, sincera), aunque art brut, usado de una forma menos estricta que lo deseado por Dubuffet, conserva la primacía indiscutible ${ }^{3}$. La anglosajona opta generalmente por outsider art a partir de la publicación de Roger Cardinal Outsider Art en $1972^{4}$. En español, la traducción de arte bruto no parece especialmente acertada, y arte marginal se presume demasiado general, por lo que es preferible emplear directamente el vocablo francés.

Dubuffet se centró en dibujos, pinturas y esculturas. Sin embargo, este campo de estudio se fue abriendo cada vez más a otro tipo de creaciones: casas o terrenos, modificados fantasiosamente por sus autores. Éstos no habían suscitado gran interés hasta la llamada de atención lanzada por el artista hacia lo "exótico cercano". En la segunda mitad del siglo veinte se van iniciando diferentes investigaciones sobre estos enclaves, clasificados en otros idiomas como outsider environments o environnements (entornos) $)^{5}$. Juan Antonio Ramírez propone una simbiosis terminológica en castellano que recalca la imbricación y la novedad de estos ejemplos: escultecturas margivagantes, por estar entre la escultura y la arquitectura (escultectura), y lo marginal y la extravagancia (margivagancia) ${ }^{6}$. Estos lugares y sus creadores están dentro del magma brut pues continúan teniendo como señas de identidad la singularidad, el autodidactismo y la marginalidad.

\section{De la casa a la cueva y del jardín al bosque}

Si se recorriera el mapa de estos entornos, sería a través de carreteras secundarias y poco transitadas. Vías agrestes que conducirían por los cinco continentes, pudiendo observar la peculiaridad de cada obra así como algunas similitudes que van más allá de las fronteras nacionales. Semejanzas que nacen, en parte, del empleo de los mismos materiales ${ }^{7}$.

La piedra es uno de los más frecuentes debido a la facilidad de su obtención y al carácter imperecedero que asegura la longevidad del monumento. Es el caso de los relieves tallados en el acantilado de Rothéneuf (Francia) por el abad Adolphe-Julien Fouré (1839-1910) (Fig. 1)8. Una superficie de $600 \mathrm{~m}^{2}$ repleta de figuras, que han sido interpretadas como piratas, personajes mitológicos, religiosos e históricos. Desde el último cuarto del siglo XIX, son testigos del paso del tiempo y a pesar de que la erosión ha ido haciendo mella en sus contornos, permanecen impasibles ante el viento y las mareas, invocando otro mundo posible: "Somos atrapados por la paradoja de una obra maciza que nos transporta sin embargo a un espacio mental y que perturba nuestro sentido de la realidad" 9 .

Hay varios ejemplos españoles destacables del uso de este elemento. Longinos Ayuso, pastor de profesión, hizo surgir de los pedruscos de su terreno diferentes animales, que constituyen lo que él denominó el Safari de Arroyolugar (Toledo). La Casa de la Piedra de Porcuna (Jaén), 


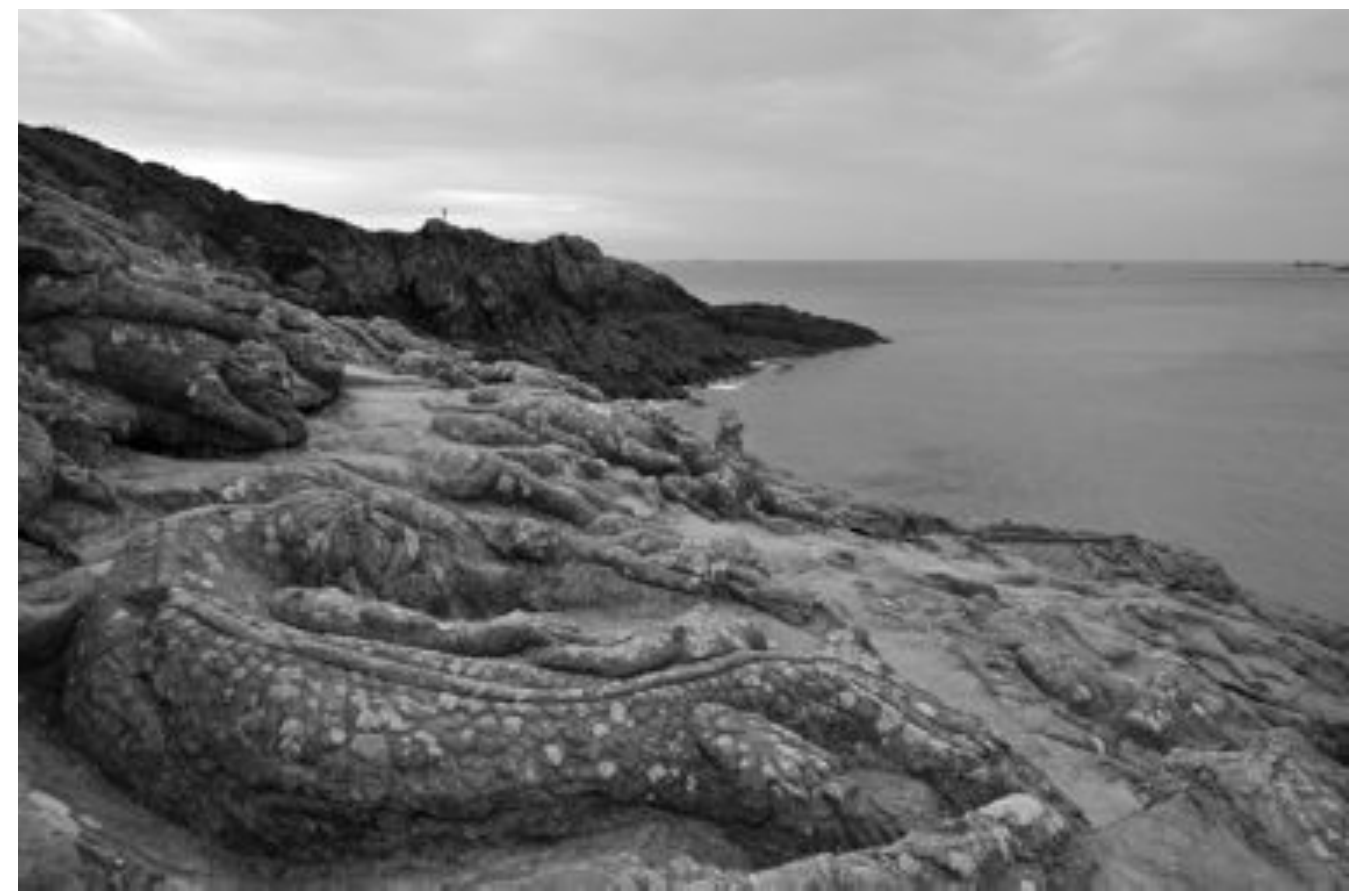

Fig. 1 Adolphe-Julien Fouré, rocas talladas en Rothéneuf (Francia), 1894-1907.

goza de cierta fama porque recibió en 1971 la Medalla de Oro al Mérito en el Trabajo ya que su artífice, Antonio Aguilera, ejecutó toda su residencia con este material. Le fue concedida la misma medalla, pero de bronce, a Lino Bueno en 1929, que no teniendo posibilidad de pagarse un techo bajo el que vivir, decidió cavar su morada en un peñasco. Así, este habitante de Alcolea del Pinar (Guadalajara) volvió a vivir en una cueva como sus antepasados, aunque ahora recreada a golpe de pico ${ }^{10}$. Las grutas son una tipología frecuente de estos creadores marginales que exploran el espacio en búsqueda de nuevas posibilidades; las más famosas son la Gruta de la Redención y la de Dickeyville, ambas en Wisconsin (Estados Unidos) (Fig. 2) ${ }^{11}$.

Las conchas son otra constante que se encuentra en construcciones no necesariamente cercanas al litoral. Su geometría perfecta llega desde el mar a la arena de la playa, huella de un mundo marino alejado del ser humano. Es habitual recoger estas joyas oceánicas y guardarlas como recuerdos. Algunos artistas las utilizan como un ingrediente más dentro de la revalorización del medio, apreciando sus formas y las sugerencias que evocan. Otros las acumulan ya obsesivamente y decoran las superficies exclusivamente con ellas, como por ejemplo la Casa de las Conchas de Montoro (Córdoba) ${ }^{12}$.

La vegetación juega un papel muy importante en este tipo de creaciones imbricadas con la naturaleza. Desde aquellos que aprovechan la poda de los arbustos y los setos para desplegar su creatividad ${ }^{13}$, a aquellos que pintan los troncos subrayando la importancia del paisaje ${ }^{14}$. Pero también todos los que de algún modo juegan con la tipología de la casa del árbol, objeto de juegos infantiles, que pasa ahora a ser desarrollada de manera espectacular. Es el caso de las cabañas que ejecutó Josep Pujiula en Arguelaguer (Gerona) desde los años setenta y que, lamentablemente, las autoridades locales derribaron casi por completo. Se trataba de un gran conjunto de túneles, torres y habitáculos realizado con ramas en el bosque al más puro estilo Robinson. Pujiula consiguió manejar la frondosidad 


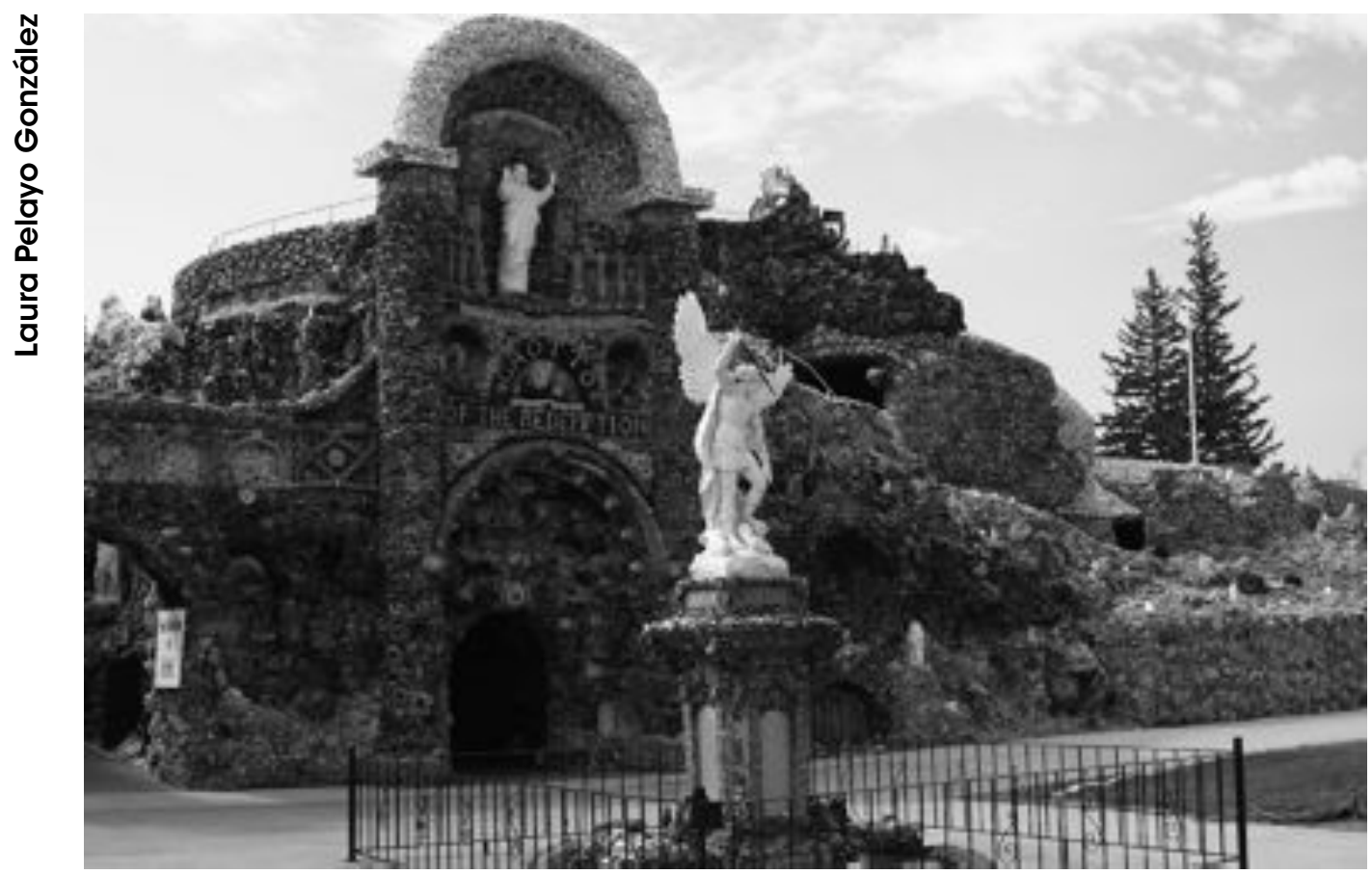

Fig. 2. Paul Dobberstein, Gruta de la Redención, Wisconsin (Estados Unidos), 1912-1954.

y ser capaz de vivir en ella. Sin embargo, no tuvo éxito en la confrontación con el sistema que tiró abajo su obra.

La convivencia e interrelación con el espacio que los rodea es esencial en estos autores brut y tiene alguno de sus mejores ejemplos en los jardines, que son convertidos en verdaderos museos al aire libre en cualquier rincón del globo: el patio que el galo Emile Taugoirdeau transforma en zoo de cemento (Thorée-les-Pins, Francia), el desierto americano que acoge las creaciones de Noah Purifoy (California, Estados Unidos), las diez hectáreas donde el indio Nek Chand compone esculturas y edificios singulares (Chandigarth, India) o el Parque de Buda que Luangpu Boonlour Sureerat ejecuta primero en Vientaiane, Laos, y después en Nong Khai, Tailandia. Los creadores expresan sus ideales en las figuras que modulan y el entorno vegetal les sirve para jugar con la idea de un mundo originario y divino ${ }^{15}$.

Este rápido viaje pone de manifiesto la importancia del lugar en el que se desenvuelven.
Nacen a partir de los materiales que la naturaleza les regala y se desarrollan como un homenaje apoteósico a las propiedades de éstos. Abogan por un hábitat en sintonía con su ecosistema y rememoran un mundo arcaico e ideal. Huyen del despilfarro, la contaminación y la masificación buscando una convivencia estable donde potenciar sus habilidades e inquietudes.

\section{Ferdinand Cheval: piedra a piedra cons- truirás tu sueño}

El ejemplo paradigmático de escultectura es el Palacio Ideal de Ferdinand Cheval (18361924), en Hauterives, Francia (Fig. 3) ${ }^{16}$. El monumento de 26 metros de largo por 14 de ancho y 10 de alto, fue construido entre 1879 y 1912 por el cartero de la localidad, que no poseía ningún tipo de formación para realizar una labor de tal envergadura.

Todo comenzó un buen día, narra el artífice, cuando en uno de sus recorridos habituales por la zona, tropezó con una piedra que le llamó especialmente la atención por su forma un tanto 


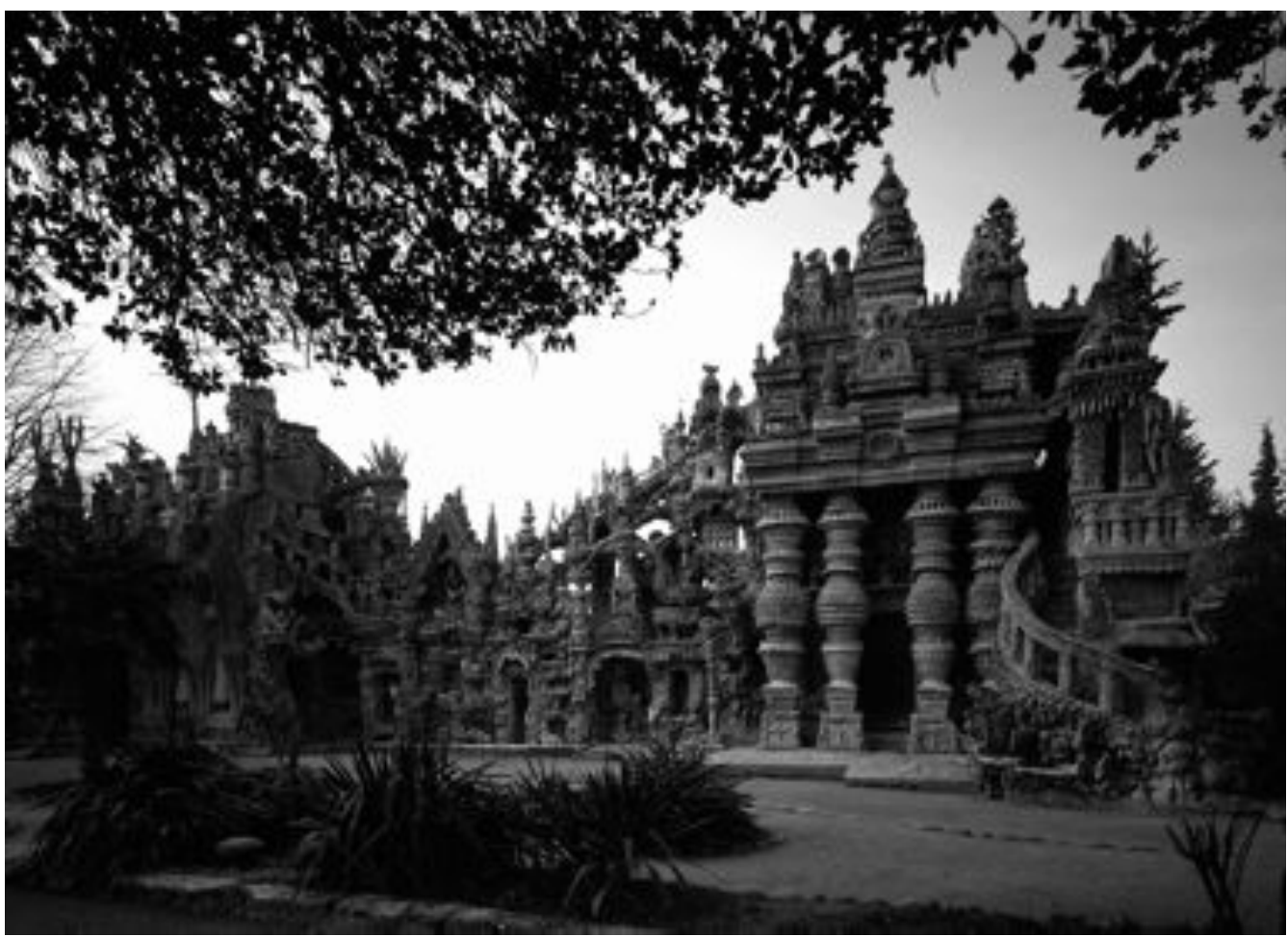

Fig. 3. Ferdinand Cheval, Palacio Ideal, Hauterives (Francia), 1879-1912.

extraña. La recogió y se la llevó a casa. Este acto, descrito por él como un momento de vital importancia, fue repetido en jornadas posteriores. Así, iba recolectando guijarros que despertaban su curiosidad y amontonándolos en su propiedad. Más adelante, decidió emplearlos para erigir una edificación que poco tiene que ver con la arquitectura tradicional. Parte de un esqueleto de alambre recubierto de cemento donde se acoplan piedras y conchas; un macizo rocoso de donde emergen un templo hindú, una mezquita, varias figuras de la Antigüedad, gigantes, sepulcros, un castillo medieval e incluso un chalet suizo. Sus fuentes son orientales, antiguas y fantásticas: le influyeron especialmente su servicio militar en Argel, la Exposición Universal celebrada en París en 1878 y los grabados y la literatura a la que pudo haber tenido acceso.

El resultado de esta mezcolanza está fuera de lo que cabría esperar encontrar en los aledaños de esta población. Sus vecinos, de hecho, creyeron que había enloquecido, aunque le deja- ron continuar su faraónica andadura porque no vieron que esta actividad supusiera algún peligro para ellos. De este modo, este cartero rural se volcó en su construcción durante más de treinta años, comprando los terrenos colindantes a su finca para poder agrandarla cada vez más. Ubicada entre los árboles, surgía de ellos como una aparición fantasmagórica. Los surrealistas se interesaron por esta huella de otra realidad más primitiva y fantasiosa, la visitaron y alertaron de su carácter de ensoñación.

El grupo francés no fue el único en valorar el trasfondo onírico del palacio, el historiador del arte Michel Thévoz ha hecho también hincapié en este aspecto y ha señalado que durante doce años Cheval lo imaginó sin llevarlo a cabo y que cuando finalmente se puso a ello fue, principalmente, de noche ${ }^{17}$. Además, plantea la migración geográfica e histórica que el autor desarrolla al mezclar influencias muy dispares, como si se produjese un fenómeno similar al de condensación que tiene lugar en los sueños. 
El mismo artista deja patente estas sugerencias en sus memorias e inscripciones:

"Todo lo que tú ves, transeúnte

es la obra de un campesino

de un sueño yo saqué

la reina del mundo"18.

Cabe destacar que realizó él solo este proyecto, asumiendo también completamente sus costes. Volcó así su tiempo y su dinero en lo que fue la obra de su vida. Este compromiso y dedicación le llevó a tomar la decisión de que fuera en la cripta que había construido con sus propias manos donde se le enterrase. Sin embargo, las autoridades le avisaron de la imposibilidad legal de su deseo. Un impedimento que le llevó a comenzar un nuevo trabajo en el cementerio local: la Tumba del Silencio y del Eterno Retorno, de similares características al anterior, pero de menor envergadura.

Como ocurre con la mayor parte de estos enclaves, tras el fallecimiento del autor, comenzó un período de abandono que condujo a un deterioro creciente. Afortunadamente, en 1968, el Ministro de Cultura francés André Malraux abrió el proceso correspondiente para que pasase a ser inscrito como monumento histórico francés ${ }^{19}$. Tras su aprobación, el Estado realizó las inversiones oportunas para su restauración y conservación, además de su habilitación como museo para que fuese abierto al público.

\section{El Palacio Ideal y la naturaleza: conchas habitadas e imperios salvajes}

El Palacio Ideal no encaja satisfactoriamente ni en la categoría de arquitectura ni en la de escultura. A primera vista se relaciona mejor con la primera de ellas, pero su tratamiento y ejecución lo vinculan con la segunda. Repleto de imágenes e inscripciones, el conjunto se va modificando con el tiempo sin seguir un proyecto determinado y fijo desde sus orígenes. La propia piedra, de la que nace la idea y a través de la cual se desarrolla, modula con sus cualidades intrínsecas el sistema de cavidades, pasillos y balconadas (Fig. 4).

El hecho de que sea el producto de una persona que no ha recibido la formación necesaria, ni por una escuela ni por un maestro, es una causa importante a tener en cuenta en la libertad en el empleo y la combinación de técnicas. Pero asimismo, es justo añadir la relevancia de que el creador se sienta "al margen": al margen de la ciudad, de los circuitos artísticos oficiales, de lo obligatorio y de lo normalizado. Esta capacidad para desvincularse de lo tradicional en un campesino, un agricultor, o, en este caso, en un cartero hace que su obra sobresalga por su novedad no sólo en su medio local y rural, sino también, en un contexto más general, dentro del panorama francés de finales del siglo XIX y principios del XX.

Es esencial que no se trate de un encargo y que no nazca orientado hacia una futura venta, sino que parta de la necesidad de un individuo y se vincule a él de por vida. El deseo de Cheval de ser enterrado ahí es común a otros autores como por ejemplo el español Máximo Rojo, que ideó una tumba para él y su esposa dentro de su jardín de esculturas de cemento. Los artífices están ligados permanentemente con sus creaciones, en las que invierten el máximo posible de horas y gran parte de sus ahorros. Se fusionan con ellas volcando sus inquietudes, su pasado y su filosofía. La escultectura es suya y sólo suya, fruto de sus ambiciones y de su único empeño, constancia y esfuerzo. Se vanaglorian de haberlas realizado sin la ayuda de nadie. El único apoyo que Cheval reconoció es el de aquella a la que consideró coautora de su legado, pues hablaba del palacio como "la escultura de la

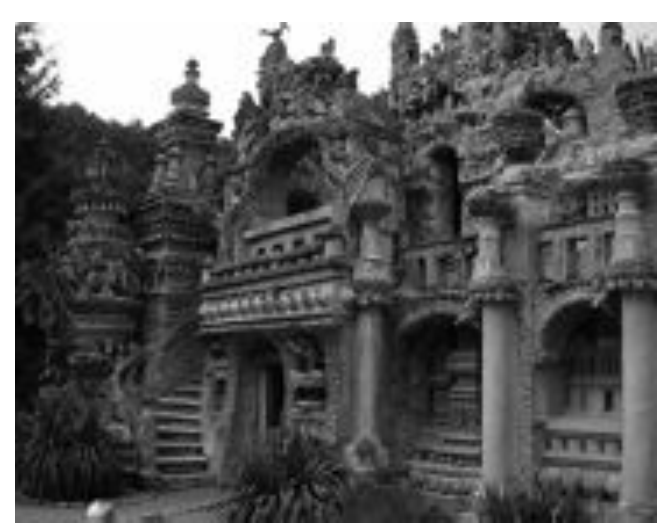

Fig. 4. Ferdinand Cheval, Palacio Ideal, Hauterives (Francia), 1879-1912. 
Naturaleza" y añadía: "Puesto que la naturaleza quiere hacer escultura, yo, yo haré albañilería y arquitectura"20.

La erosión previa de los elementos se combinó así con la inflingida por él de modo artificial. No es difícil imaginarlo tallando en la oscuridad, iluminando con una vela las imágenes que poco a poco brotan a la superficie, o paseando por las cercanías, mirando al suelo y agachándose para recoger las maravillas que el camino le ofrece. Porque su invención se basa, además de en la fantasía oriental o imaginaria, en la apreciación de su entorno. Desde el encuentro fortuito que le inicia en esta tarea hasta las formas de las grutas, las plantas, los minerales y los fósiles que son objetos de su inspiración.

En 1933, Breton publica en Minotaure "Le Message automatique"21. El escritor parte de la famosa lección que Leonardo da Vinci impartía a sus alumnos proponiéndoles observar un muro hasta que las formas se combinaran entre sí creando escenas imaginarias que ellos entonces copiarían. Este ejercicio sirve para introducir el automatismo practicado por los surrealistas en textos y dibujos. Un procedimiento que se proclama como semejante al de los médium que ejecutan dibujos extraordinarios bajo el dominio de un supuesto espíritu. Augustin Lesage (18761954) es uno de ellos, afirmó que eran los muertos quienes dirigían su pincel y su pluma (Fig. 5), pero Breton avisa en este artículo del pasado de Lesage como minero y relaciona sus intrincadas estructuras desplegadas sobre el papel con las que debió de recorrer en sus largas jornadas de trabajo bajo tierra. En cuanto a Cheval, compara, de manera similar, sus construcciones con el paisaje propio de su comarca:

Lesage es minero, lo que hace posible que su ojo haya sido impresionado por la estructura de algunas galerías subterráneas; así como hay sobradas razones para admitir que el cartero Cheval, que permanece como el maestro indiscutible de la arquitectura y la escultura mediúmnicas, fue acosado por los aspectos de suelo de gruta, de vestigios de fuentes petrificadas de esta región de Drôme donde, durante treinta y seis años, efectuó a pie su ronda22.
Para el francés no hay nada de sobrenatural en los trazos provenientes de estos supuestos receptores de fuerzas y poderes de otro mundo. El mensaje del que son portadores estaría al alcance de cualquier persona que diera rienda suelta a este lenguaje común a todos y a todo.

Casi tres décadas después, en 1962, Breton redactará la introducción de Les inspirés et leurs demeures, donde Gilles Ehrmann presenta varias escultecturas, entre ellas el Palacio Ideal23. Este preámbulo lleva por título "Belvédère" y en él expone su interés hacia un arte que se aparta del circuito comercial y no se presta fácilmente a la clasificación del especialista. La mayor parte de los ejemplos analizados en este estudio parten de la tipología de la casa y Breton, en base a ello, realiza la siguiente comparación: "Respecto a lo que les rodea, que les sobrevivirá mal que bien, están en la situación de los moluscos testáceos, en relación a su concha, que han segregado a partir de los tegumentos adecuados" 24 .

Es decir, son indisociables de esta morada que han levantado de forma autodidacta, ins-

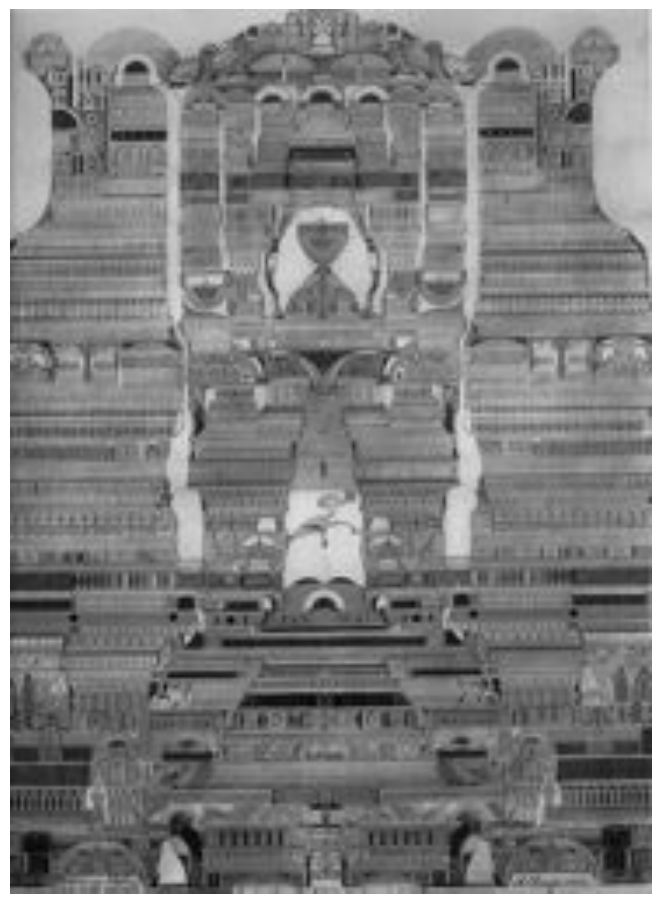

Fig. 5. Augustin Lesage, Una composición simbólica del mundo espiritual, Collection de l'Art Brut, Lausanne (Suiza), 1923. 
tintiva, tal y cómo las aves se afanan en la elaboración del nido o las abejas, de la colmena ${ }^{25}$. Esa manera natural, universal, de búsqueda de refugio, por un lado, y de desarrollo de impulsos creativo-artísticos, por otro.

Bernard Rudofky, autor de L'architecture insolite (1977), avisa del sentido innato de construcción de la mayoría de los animales y de cómo estos instintos se pierden con la domesticación ${ }^{26}$. El hombre sería entonces un ser domesticado que, cual pájaro enjaulado, habría dejado de inventarse su propio hogar. Se podría decir que los escultectos margivagantes dan, por el contrario, rienda suelta a estos impulsos. No se conforman con los cimientos tradicionales ni las nuevas edificaciones impersonales, y deciden elaborar con sus propias manos los refugios singulares que ocupan ${ }^{27}$. Imperios del habitante. Refugios de los que se adueñan, rechazando el esclavismo del simple usuario.

\section{Máximo Rojo y su jardín enciclopédico}

Ferdinand Cheval es la clave para entender buena parte de los rasgos comunes a estos artistas y su revalorización inicial. Una historia que finaliza con la inclusión de su legado dentro del patrimonio nacional y su difusión gracias a su aparato museístico. El español Máximo Rojo va a mostrar otros patrones de los entornos de las últimas décadas del siglo veinte no mencionados hasta ahora. Además, su cruzada no concluye tan satisfactoriamente y revela un futuro de deterioro, expolio y olvido al que se debe hacer frente.

Máximo Rojo (1912-2005)28 fue un campesino sin estudios que trabajó como pastor y agricultor durante toda su vida, pero que a raíz de su jubilación en 1979 comenzó a transformar su antigua era de trillar en un museo al aire libre (Fig. 6) ${ }^{29}$. Este espacio, ubicado en Alcolea del Pinar (Guadalajara), alberga unas trescientas esculturas. Algunas son de pequeño tamaño, pero otras superan los tres metros de altura, convirtiéndose en verdaderos monumentos conmemorativos o arquitecturas donde uno puede llegar a introducirse ${ }^{30}$. El material más utilizado es el cemento, combinado con piedras, vidrio y metal, pero también aprovecha partes de electrodomésticos, sillas, pelotas, tapas, volantes, vasos, etc.

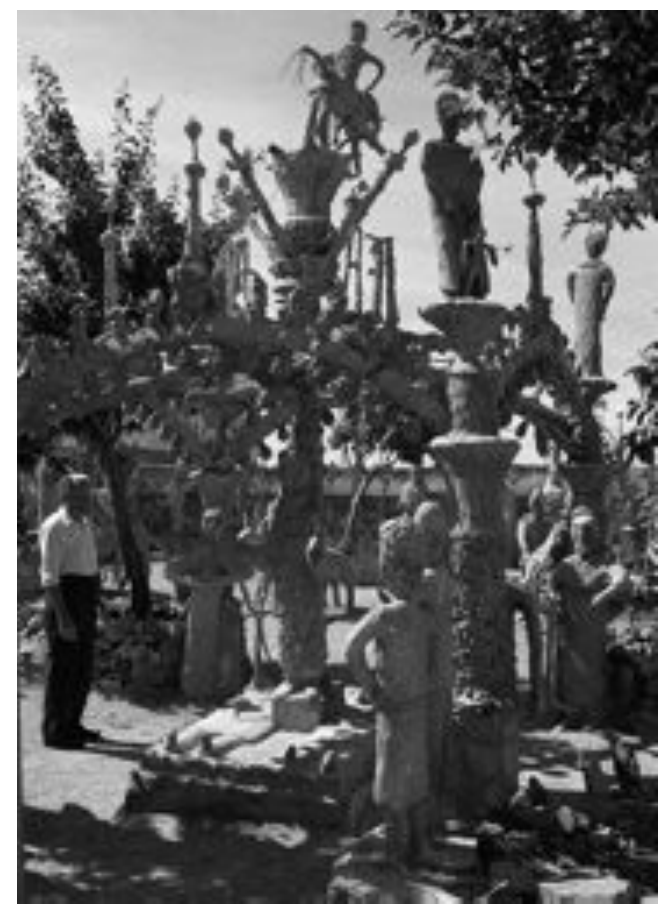

Fig. 6. Máximo Rojo junto al monumento que pretendía fuese su tumba y la de su esposa. Máximo Rojo, jardín de esculturas en Alcolea del Pinar (Guadalajara), 1979-2004.

Su jardín estaba abierto al público. Él lo enseñaba en una peculiar vista guiada donde identificaba las piezas, señalaba y profundizaba en su contenido, añadía anécdotas y argumentaba acerca de ciertos asuntos que él consideraba relevantes, como la importancia de la educación o el horror de la guerra ${ }^{31}$. Su filosofía también ha quedado patente en varios escritos suyos que se han conservado: autobiografías, reflexiones de carácter general y unos cuadernos donde, a modo de catálogos, registraba y comentaba sus trabajos.

La temática de sus piezas es amplísima: Agustina de Aragón, Monumento a Colón, Un tesoro hay en la viña, El Quijote, La zorra y las gallinas, Adán y Eva (Fig. 7), Monumento a la mujer trabajadora, Magallanes y Juan Sebastián Elcano, Los tres tiempos de la vida, Tierno Galván, etc. Abarca la historia, el arte, la literatura, la religión, la agricultura, la tecnología, la naturaleza y su propia moral. De lo místico a lo cotidiano, del nacimiento a la muerte, de los cinco continentes 


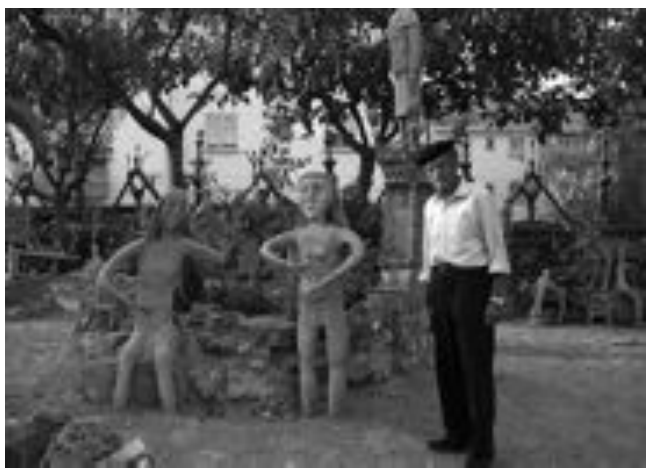

Fig. 7. Máximo Rojo junto a Adán y Eva. Máximo Rojo, jardín de esculturas en Alcolea del Pinar (Guadalajara), 1979-2004.

a su comunidad. Hay en él un deseo de construir una recreación de su mundo interior, de sus conocimientos y de sus experiencias.

Este afán por ilustrar al prójimo y aspirar a recoger todas las historias y criaturas de nuestro planeta recuerda al espíritu enciclopédico, marcado por una fe en el porvenir con la guía de la educación y la razón. Un manual en tres dimensiones, dispuesto para ser experimentado. Una recopilación de elementos que también se puede poner en paralelo con los gabinetes de curiosidades, donde se clasificaban los objetos según pertenecieran al universo de lo exótico, de los adelantos modernos, lo natural o los llamados artificialia, creados por el hombre. Todos estos grupos son recogidos por Rojo en su monumental proyecto que bebe de esos pre-museos tal y como lo hacen otros margivagantes de la segunda mitad del siglo veinte que, tanto por la recolección de sus tesoros (basura reciclada) como por la amalgama producida por su exposición, concuerdan con los cuartos de maravillas en los que se asienta gran parte de la cultura y el saber occidental.

Este artista, además de la conquista temática que le lleva a tratar cualquier tipo de asunto, ejerció una verdadera conquista espacial. Por un lado, en su era, cada vez más y más poblada y, por el otro, en su residencia, también en este municipio, donde transformó las fachadas introduciendo relieves en los paramentos y disponiendo esculturas exentas en las ventanas, sobre el tejado y en el patio trasero. Una pulsión que puede relacionarse con el horror vacui tan típi- co de los pintores brut, invadidos por un movimiento creador que parece no tener límites; pero también con una tendencia a adueñarse del ambiente y personalizarlo, en lo que se podría denominar una "domesticación del territorio" 32 .

Tanto la casa como el jardín-museo fueron donados por Máximo Rojo al Ayuntamiento de Alcolea del Pinar. No teniendo hijos, quiso asegurarse de que tras su muerte las lecciones petrificadas que había creado le sobrevivieran y siguieran sirviendo a futuros visitantes. Sin embargo, una vez acaecido su fallecimiento, éstos permanecen cerrados al público y se deterioran a pasos agigantados. No se realiza ningún tipo de labor ni de restauración ni de conservación; su legado continúa solo a la intemperie, bajo la lluvia, la nieve y los esporádicos vándalos que frecuenten la zona. El mundo contemporáneo pierde algunas de sus creaciones más enigmáticas y reveladoras a causa de la dejadez, el conservadurismo y la falta de inversión. El muestrario fantasioso de la memoria se hace ruina y con ello una parte de la historia del arte se desvanece, como debieron de hacerlo otras antes.

\section{Reciclando quimeras, modulando dese- chos}

Las esculturas de Máximo Rojo conviven y dialogan con la vegetación. El terreno de la era, inicialmente árido, fue transformado en un vergel. Árboles y plantas variadas, incluso un pequeño huerto, se combinan con fuentes, bancos y un merendero. El aspecto del jardín cambia según las estaciones y los colores de las hojas modifican las obras con sus brillos y tonos. Las piezas conviven con la naturaleza y se mezclan con ella. Se producen sinestesias variadas: el sentido del oído, del olfato y de la vista, fusionan dos mundos en uno. El pájaro real se codea con su semejante de cemento, que saluda al visitante desde su rama grisácea, mientras los ladridos que se escuchan de fondo parecen salir de ese can que se yergue permanentemente inmóvil ${ }^{33}$.

Su disposición nada tiene que ver con la de un museo tradicional. No hay forma de controlar su iluminación ni su temperatura: todo varía a lo largo del día y de los meses. Además, su artífice se encargaba de que este vaivén continuara al realizar modificaciones periódicas: añadía nue- 
vos apliques, insertaba nuevos animales o aprovechaba una restauración para disponer nuevas figuras. Un conjunto en continuo proceso que nunca daba por finalizado.

La creación tenía así su propia vida. Se alimentaba no sólo de ingredientes "naturales" como piedras o arena, sino de cualquier objeto que pudiera ser reutilizado. Este español reciclaba muebles, juguetes, neumáticos y todo tipo de productos, que eran despedazados y empleados como esqueleto de sus construcciones. Las formas de estos bienes de consumo eran recubiertas de materia, camufladas y transformadas en nuevos exponentes del arte marginal. Esferas terrestres nacidas de balones de fútbol, espadas medievales fruto de pequeños filamentos de metal o árboles creados a partir de la superposición de tubos que parecían ya inservibles.

Este reciclaje es común a gran número de margivagantes que encuentran en los desechos de su sociedad los gérmenes de su trabajo. Además de servirse de esta práctica para exponer el sinsentido de una superproducción desbordada, ejemplifican la posibilidad de una existencia más económica y responsable. Hogares realizados a base de platos rotos, muros cimentados con botellas o parques jalonados de chatarra. La casa de Picassiette (Chartres, Francia), las Torres Watts en Los Ángeles (California, Estados Unidos) o The Orange Show (Texas, Estados Unidos) dan muestras del florecimiento que puede producirse en cualquier lugar y con cualquier cosa.

Esta otra constante brut sigue situándose en los mismos parámetros ya comentados: la utilización y revalorización del medio en el que se encuentran, y la búsqueda de una armonía y equilibrio con él. Ferdinand Cheval recogía sus materiales en los senderos del bosque a finales del siglo XIX y Máximo Rojo hizo lo propio en las calles de su localidad un siglo después. Síntomas del cambio del paisaje rural; porque las huellas que ambos dejan tras de sí son trazadas no sólo por sus vivencias y fantasías personales sino también por la época en la que viven.

Los tradicionales nidos de pájaros a base de ramas y hojas, dejan paso a veces a otras construcciones realizadas por estas aves con la basura que encuentran en las cercanías. Algunos de estos artistas actúan siguiendo este mismo esquema, sirviéndose sin prejuicios de aquello que les rodea. Buscan el autoabastecimiento, aprovisionándose de fuentes de riqueza artística sin diferenciar las artificiales de las naturales porque todas integran su ecosistema.

En estos reductos de la creación autodidacta, el ser humano se enfrenta solo a la naturaleza y decide volver a levantar con sus propias manos el refugio que él y su familia habitarán, proveyéndose de aquello que el terreno le brinda. Trabaja afanosamente y se deja llevar por sus impulsos de grandeza y sus sueños infantiles: palacios exóticos, grutas misteriosas, oasis religiosos y cabañas de Robinsones. Se siente libre para modular el mundo con el que siempre fantaseó y crea, apasionadamente y sin descanso, a partir de sus pensamientos más profundos. Deja un legado que espera le sobreviva: la guarida donde ha grabado sus recuerdos y deseos arañándolos en la roca, escarbándolos en el suelo. 


\section{NOTAS}

1 Este término francés puede ser traducido por arte bruto, aunque no es del todo satisfactorio pues se pierden parte de las connotaciones originarias.

2 Para más información sobre el art brut véanse especialmente: $M$. Thévoz, L'art brut, Skira, Ginebra, 1995; R. Colin, Outsider Art. Alternativas espontáneas, Destino, Barcelona, 2002 y L. Peiry, L'Art Brut, Flammarion, París, 2006.

Algunos de los textos más importantes de Jean Dubuffet están traducidos al español en: J. Dubuffet, $E$ I hombre de la calle ante la obra de arte, Debate, Madrid, 1992.

${ }^{3}$ Para una breve historia del art brut y su terminología ver: C. Delevaux, L'art brut un fantasme de peintre: Jean Dubuffet et les enjeux d'un discours, Palette, París, 2010.

${ }^{4}$ R. Cardinal, Outsider Art, Studio Vista, Londres, 1972.

Sobre la cuestión terminológica y su problemática en lengua inglesa véase: M. D. Hall y E. W. Metcalf (editores), The Artist Outsider. Creativity and the Boundaries of Culture, Smithsonian Institution, Washington-Londres, 1994.

${ }^{5}$ A pesar de no haberse llegado a un consenso y a barajarse diferentes posibilidades, en las publicaciones extranjeras "entornos" es la opción más frecuente, matizada con diferentes adjetivos: brut, outsider, visionario, fantástico, etc. Destacar los trabajos de John Maizels sobre este tema, que gozan de una mayor difusión: J. Maizels y D. von Schaewen, Fantasy Worlds, Taschen, Colonia, 1999 y J. Maizels, Raw Creation. Outsider Art and Beyond, Phaidon, Londres, 1996, pp. 158-225.

${ }^{6} \mathrm{~J}$. A. Ramírez (director), Escultecturas margivagantes. La arquitectura fantástica en España, Siruela, Madrid, 2006, pp. 20-23.

${ }^{7}$ Se ha escogido el material como guía de este breve análisis. Otras características comunes son, por ejemplo, las que parten de sus autores que no han recibido formación artística, no tienen relación con el mundo del arte y desarrollan esta labor en sus ratos libres o a raíz de su jubilación.

8 Los entornos mencionados en este estudio constan en las publicaciones principales. Si se desea completar la información sobre los casos extranje- ros se recomienda consultar J. Maizels y D. von Schaewen, Fantasy Worlds, op. cit. y J. Maizels, Raw Vision. Outsider Art Sourcebook. The Essential Guide to Outsider Art, Art Brut, Contemporary Folk Art \& Visionary Art from around the world, Raw Vision, Watford, 2002.

En cuanto a los ejemplos españoles la única edición publicada hasta la fecha es J. A. Ramírez (director), Escultecturas margivagantes..., op. cit. La revista Raw Vision, especializada en este tipo de arte, cuenta con un breve mapeado del territorio español en el artículo también pionero: J. A. Ramírez, "Fantastic Monuments", Raw Vision, n 60, otoño 2007, pp. 54-61.

${ }_{9}^{9}$ M. Thévoz, L'art brut, op. cit., p. 37.

${ }^{10}$ En Alcolea del Pinar se encuentran, además de la casa de Lino Bueno, el Monasterio de Perdizes y el jardín de esculturas de Máximo Rojo, que se tratará al final de este artículo.

${ }^{11}$ La Gruta de la Redención fue iniciada por el cura Paul Dobberstein en 1912 e inspiró a Mathias Wernerus, también religioso, para la ejecución de un proyecto parecido en Dickeyville.

${ }^{12}$ Existen otros ejemplos similares dispersos por la geografía española: Villa Pechina en Tavernes de Valldigna (Valencia), Casa de Azuaga (Badajoz) y la Casa de Les Conches en Tazones (Asturias).

13 Por ejemplo los arbustos y los setos de contornos fantasiosos de Losar de la Vera, en Cáceres, y de Bishopsville, en Carolina del Sur, Estados Unidos. Separados por miles de kilómetros, pero unidos por un procedimiento común.

${ }^{14}$ Los árboles pintados en Pla de Mallorca por el médico alemán ya jubilado Marius Fischler son una muestra de estas inquietudes.

15 Este simbolismo es expuesto explícitamente en algunas ocasiones, como en el Jardín del Edén (Kansas, Estados Unidos) de Samuel Perry Dinsmoor, o el Jardín del Paraíso (Georgia, Estados Unidos) del reverendo Howard Finster, plagado de mensajes religiosos y unas 35.000 obras.

${ }^{16}$ Para más información sobre Ferdinand Cheval véase la obra de referencia: J. Jouve, C. Prevost y C. Prevost, Le palais idéal du facteur Cheval. Quand le songe devient la réalité, Moniteur, parís, 1981.
${ }^{17}$ M. Thévoz, L'art brut, op. cit., pp. 31-36.

18 Inscripción de Ferdinand Cheval en el Palacio Ideal. Traducción del francés a cargo de la autora.

${ }^{19}$ El Palacio Ideal se inscribió finalmente en 1969. Encuanto a la Tumba del Silencio y del Eterno Retorno, fue en 1975 cuando pasó a formar parte del inventario suplementario de monumentos históricos de Francia.

${ }^{20}$ M. Thévoz, L'art brut, op. cit., p. 32. Traducción del francés a cargo de la autora.

${ }^{21}$ A. Breton, "Le Message Automatique", Minotaure, n 3-4, 1933, pp. 55-65.

${ }^{22}$ A. Breton, "Le Message Automatique", op. cit., p. 60. Traducción del francés a cargo de la autora.

23 A. Breton, "Belvédère", en G. Ehrmann, Les inspirés et leurs demeures, Le Temps, París, 1962 (no paginado).

${ }^{24} \mathrm{~A}$. Breton, "Belvédère", op. cit. (no paginado). Traducción a cargo de la autora.

25 Algunos autores han aludido ya a este paralelismo entre las construcciones brut y los animales. Véase J. A. Ramírez, Escultecturas margivagantes..., op. cit., pp. 29-30.

26 B. Rudofsky, L' Architecture insolite: une histoire naturelle de l'architecture concernant, en particulier, ses aspects le plus souvent négligés ou totalement ignorés, Tallandier, París, 1979.

${ }^{27}$ Algunos especialistas señalan el acto revolucionario que ejecutan estos artífices, especialmente en fechas más recientes, al doblegarse contra la monotonía de las edificaciones modernas donde el propietario tiene escasas posibilidades de singularización. Véase por ejemplo: G. R. Collins, M. Schuyt y J. Eiffers, Les bâtisseurs du rêve, Hachette, París, 1980, p. 10.

${ }^{28}$ Además de en las dos obras ya mencionadas de Juan Antonio Ramírez sobre los escultectos margivagantes españoles, este estudio sobre Máximo Rojo se basa en el trabajo de investigación desarrollado por la autora sobre este creador entre 2006 y 2007, pendiente de publicación.

En 2011 Guillermo G. Peydró filma el documental El jardín imaginario, que indaga en las motivaciones de este 
escultecto español y saca a la luz la problemática de su obra.

$29 \mathrm{El}$ origen humilde de Máximo Rojo y sus inicios en esta actividad a una edad avanzada son características comunes a otros margivagantes. En cuanto a la franja de edad a la que pertenecen estos artistas, Michel Thévoz subraya el hecho de que si en las primeras décadas lo brut podía encontrarse preferentemente en los asilos psiquiátricos y bajo la coartada de una supuesta locura, es ahora en la vejez donde prosperan mejor estos "frutos". Thévoz ve en los ancianos a los nuevos parias de la sociedad que alejados del consumo y otras coacciones pueden explorar más libremente su creatividad.

Véase: M. Thévoz, Requiem pour la folie, La Difference, Paris, 1995.

${ }^{30}$ Muchos entornos brut recogen arquitecturas trasladadas mediante sus técnicas a su propio jardín. Esta miniaturización es apreciable especialmente en la Casa Azul de Euclides Ferreira da Costa, realizada entre 1957 y 1977 en Dives-sur-Mer (Francia), donde este portugués rememora templos cristianos a través de pedazos de vajilla de diferentes colores.

${ }^{31}$ El caso de Máximo Rojo sirve para ejemplificar el interés de la mayoría de estos artífices por dar a conocer su quehacer. Por un lado, se trata de una forma de dejar una huella tras de sí que hable al futuro y, por el otro, de establecer una conexión con el presente. En cuanto a este segundo aspecto, nos referimos a la comunicación que se establece por medio de estas historias desplegadas visual y verbalmente entre un individuo y su vecino o el turista de paso con el que puede interactuar. Erika Doss señala también la finalidad de hacer algo para los otros como un medio para conectar con ellos y el mundo. Podemos decir así que Máximo Rojo, cuya historia personal desvela cierto aislamiento en su comunidad, tiende un puente para con el mundo mediante esta actividad.

Véase: E. Doss, "Wandering the Old, Weird America. Poetic Misings and Piligrimage. Perspectives on Vernacular Art Environments", en Sublime Spaces \& Visionary Worlds: Built Environments of Vernacular Artists, Princeton Architectural Press, Nueva York, 2007, p. 55.

32 J. Martinon, "Les espaces corrigés", Traverses, n 5-6, octubre 1976, p. 149.

${ }^{33}$ Hay que destacar que los entornos brut no son vistos, sino experimentados. Uno se sumerge en la creación, recorriéndola físicamente y apreciándola desde cualquier ángulo. Máximo Rojo idea su jardín-museo como un lugar por donde transcurrir con un itinerario establecido por él, de modo que no se trata de mirar sino de introducirse en él y vivirlo. 